\title{
Corrigendum
}

\section{The diagnostic and prognostic utility of claudin expression in renal cell neoplasms}

Mirna Lechpammer, Murray B Resnick, Edmond Sabo, Evgeny Yakirevich, Wesley O Greaves, Katherine T Sciandra, Rosemarie Tavares, Lelia C Noble, Ronald A DeLellis and Li J Wang

Modern Pathology (2009) 22, 321; doi:10.1038/modpathol.2008.149

Correction to: Modern Pathology advance online publication, 27 June 2008; doi:10.1038/modpathol.2008.116

a

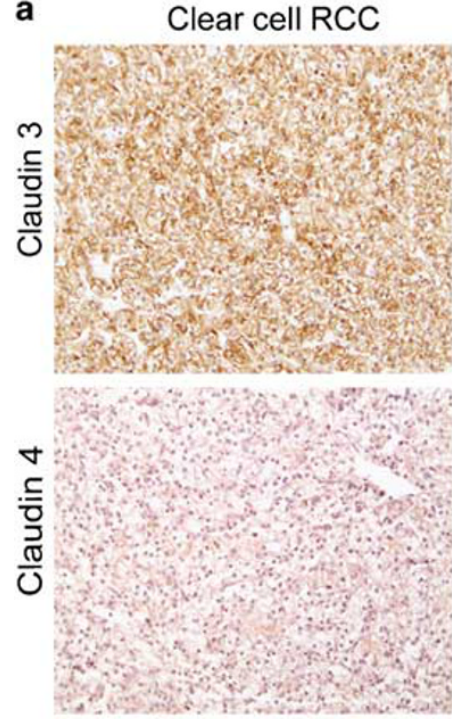

Papillary RCC

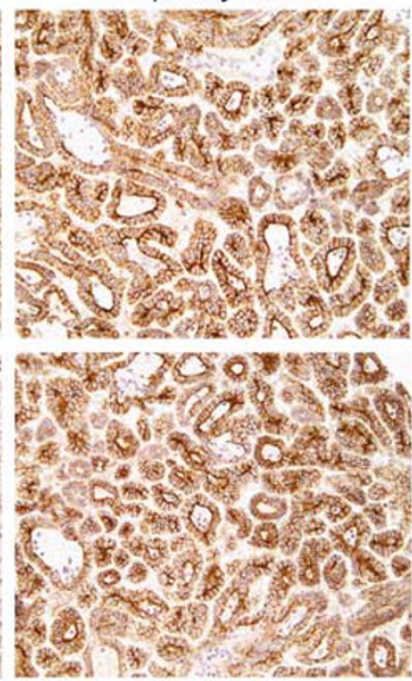

b

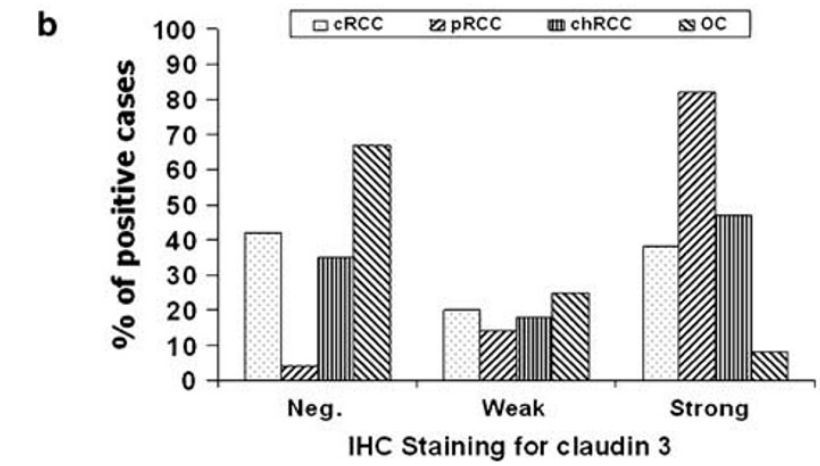

Following the online publication of this article, the author found an error in Figure 3, panel C; the label should be 'IHC Staining for claudin 4' instead of 'IHC Staining for claudin 3.'
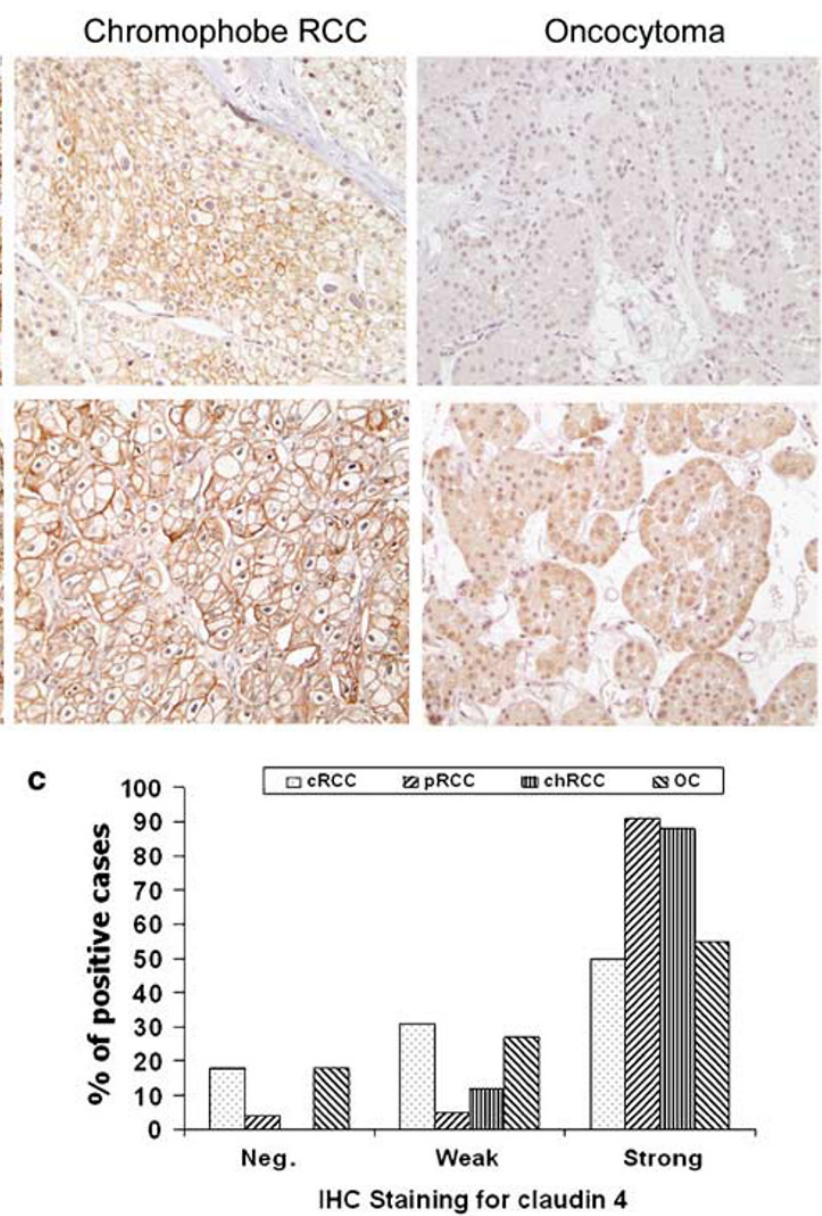